\title{
INFECCIÓN EXPERIMENTAL EN RATONES CON LARVA MIGRANS OCULAR
}

\author{
EXPERIMENTAL OCULAR LARVA MIGRANS INFECTION \\ IN MICE
}

STANGOGIANNIS DE ${ }^{1}$, MARVAL H${ }^{2}$, MORENO DE MM², MARTÍNEZ M ${ }^{3}$, STANGOGIANNIS DC ${ }^{4}$

\begin{abstract}
RESUMEN
Objetivo: Caracterizar las posibles alteraciones histológicas en el globo ocular de ratones infectados masivamente con Toxocara canis, durante los estadios agudos y crónicos de la infección.

Método: Se realizó un estudio experimental, prospectivo in vivo, con globos oculares derechos e izquierdos correspondientes a cinco grupos de cuatro ratones cada uno (dos blancos $(\mathrm{A} / \mathrm{J})$ y dos negros (C57/BL) infectados por vía endovenosa con 1.000 huevos embrionados de Toxocara canis. Los ratones fueron sacrificados de forma secuencial post infección (3-180 días), se realizó microscópica convencional e histopatología fotografiadas.

Resultados: Todos los ratones mostraron algún grado de daño ocular en uno o ambos ojos. La retina era la capa más afectada con edema, hemorragia y cambios degenerativos severos. Otras alteraciones incluyeron reacción inflamatoria de la córnea, obliteración de la cámara anterior con material fibrinoide, asimismo, se evidenció cambios en la histología normal de la uvea y del cristalino. En dos ojos de ratones se encontraron segmentos de larva en la retina, sin reacción inflamatoria alrededor de ellos.
\end{abstract}

\begin{abstract}
Objective: To characterize the histologic alterations in the ocular globe of mice infected with eggs of Toxocara canis, during both the acute and chronic stages of the infection.

Method: Performance of an experimental, prospective study in vivo, with right and left ocular globes [using 5 groups of 4 mice in each study; 2 white $(\mathrm{A} / \mathrm{J})$ and 2 black (C57/BL)], infected by the intravenous injection of 1000 embrionated Toxocara canis eggs. The mice were sacrificed sequentially post infection (3-180 days), the eyes evaluated by conventional microscopic techniques and the histopathology findings recorded.

Results: All the mice revealed some degree of ocular damage in one or both eyes. The retina was the most affected layer with edema, hemorrhage and severe degenerative changes seen. Other alterations included inflammation of the cornea, and obliteration of the anterior chamber with fibrinoid material. We also demonstrated changes in the normal histology of the uvea and lens. In only two eyes were segments of larvae found in the retina, and in each instance there was no evidence of an inflammatory reaction around them.
\end{abstract}

Recibido: 27/6/05. Aceptado: 18/1/07.

Centro Oftalmológico San Jorge. Ciudad Bolívar Edo. Bolívar. Venezuela.

1 Licenciado en Medicina. Asociación para Evitar la Ceguera en México (APEC).

2 Doctor en Medicina. Universidad de Oriente. Núcleo Bolívar.

3 Licenciado en Medicina. Hospital Universitario de Caracas. UCV. Caracas.

4 Licenciado en Medicina. 
Conclusión: La mayoría de las alteraciones no se relacionó a la presencia de formas larvarias, sugiriendo que sean debido al efecto de productos de excreción-secreción durante la infección.

Palabra clave: Toxocariasis ocular, larva migrans ocular, histopatología T. canis, retina, T. canis.
Conclusion: Most of the changes seen were not related to the presence of larval forms, suggesting they were due to the effect of excretion-secretion products during the infective phase (Arch Soc Esp Oftalmol 2007; 82: 89-94).

Key words: Ocular toxocariasis, ocular larva migrans, T. canis histopathology, retina, T. canis

\section{INTRODUCCIÓN}

Existe un conjunto de enfermedades que predominan en zonas intertropicales la cuales han adquirido ciertas características peculiares siendo llamadas enfermedades tropicales (1).

La toxocariasis es una helmintiasis común en perros, que afecta a otros mamíferos, entre ellos al hombre, donde los parásitos reflejan un comportamiento especial originando una entidad nosológica diferente, conocida como larva migrans visceral $(2,3)$.

Las manifestaciones clínicas de este síndrome se presentan como una persistente y llamativa hipereosinofilia sanguínea, alta y sostenida por más de un año y sin síntomas concomitantes. Asimismo, se encuentra asociada a la formación de un granuloma en el polo posterior por lo que, se ha mimetizado un estado temprano de retinoblastoma induciendo la pérdida total o parcial de la visión en uno o en ambos ojos. Igualmente se ha asociado a granuloma en la retina periférica, pars planitis, endoftalmitis y uveítis. Otras menos comunes incluyen hipopión, absceso vítreo, neuritis óptica, queratitis o estrabismo secundario (4).

Muchos estudios se han realizado en animales experimentales con el objeto de establecer un animal modelo que permitiese comprender la presencia de larva migrans visceral, cada día más frecuente (1-5). Sin embargo, no ha ocurrido lo mismo con la toxocariasis ocular experimental. De ahí que en la actualidad no se tengan claros muchos aspectos de su patogenia, diagnóstico y tratamiento. Como continuación del proyecto CI-2-0000220/84-96 toxocariasis: histopatología y tratamiento nos proponemos estudiar esta patología desde el punto de vista experimental y de esta forma caracterizar las posibles alteraciones histológicas en el globo ocular de ratones infectados masivamente con Toxocara canis, durante los estadios agudos y crónicos de la infección.

\section{SUJETOS, MATERIAL Y MÉTODOS}

El esquema general a seguir para dar respuesta a los objetivos planteados permite situar al presente estudio dentro de las siguientes categorías: Experimental, Prospectivo in vivo.

Se emplearon 20 ratones de cepas blancas $(\mathrm{A} / \mathrm{J})$ y negros (C57/ BL) obtenidos del laboratorio del Bioterio del IVIC (Instituto Venezolano de Investigación Científica) donde fueron criados estas cepas cuyas siglas son internacionales, las cuales fueron agrupados en cinco grupos de cuatro ratones cada uno, dos blancos (A/J) y dos negros (C57/BL). Los huevos fueron obtenidos del intestino de perros cachorros de 2 meses de edad, se extrajeron de parásitos hembras de Toxocara cani y se disecaron, se sacaron de los úteros los huevos y se colocaron a embrionar en solución salina con 1 gota de formol por 30 días obteniendo de esta forma los huevos embrionados viables. Luego se procedió a inocular con jeringa vía oral en los ratones de cepas blancas $(\mathrm{A} / \mathrm{J})$ y negras $(\mathrm{C} 57 / \mathrm{BL})$ aproximadamente 1.000 huevos embrionados suspendidos en solución salina. En el manejo de los animales se siguieron las pautas de la Asociación para la Investigación en Visión y Oftalmología (ARVO en inglés) para el uso de animales en investigación oftalmológica; así como también, fue sometido al comité de investigación científica de la Universidad de Oriente, Estado Bolívar, Venezuela. Para el sacrificio se utilizó el siguiente esquema:

Grupo I: 3 días post-infección.

Grupo II: 7 días post-infección.

Grupo III: 60 días post-infección.

Grupo IV: 100 días post-infección.

Grupo V: 180 días post-infección.

Se realizaron cortes histológicos, secundarios, de 4 micras los cuales fueron coloreados con hematoxilina-eosina y observados y fotografiados en un microscopio Zeiss. 


\section{RESULTADOS}

La figura número 1 corresponde a la imagen de las estructuras oculares de un ratón normal.

A partir del séptimo día post-infección, en todos los animales infectados (ratones blancos y negros), se observaron alteraciones histológicas principalmente en el polo posterior que se intensificaban a medida que pasaba el tiempo de infección. La retina fue la estructura ocular mayormente afectada observándose como primeros rasgos patológicos: edema, congestión vascular, disgregación de las capas y organizaciones celulares atípicas particularmente en forma de rosetas en las capas nucleares externas e internas (fig. 2) y en aquellos animales con infecciones superiores a los dos meses, la retina presentó hemorragia intensa subretiniana y retro-

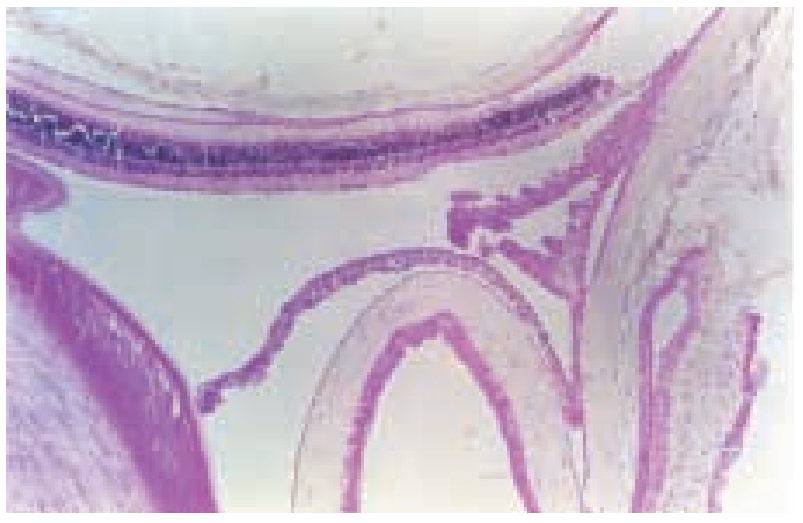

Fig. 1: Ratón normal.

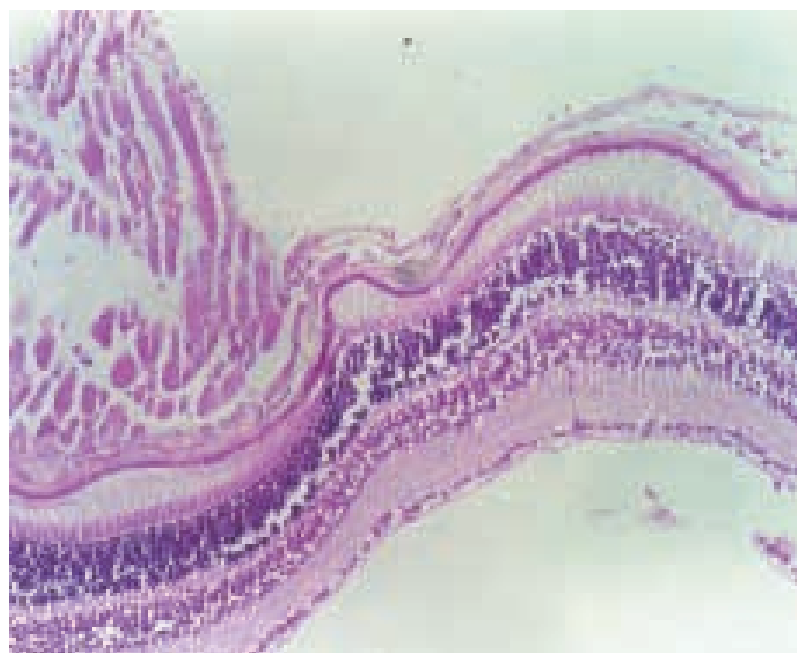

Fig. 2: Rosetas en capas nucleares.

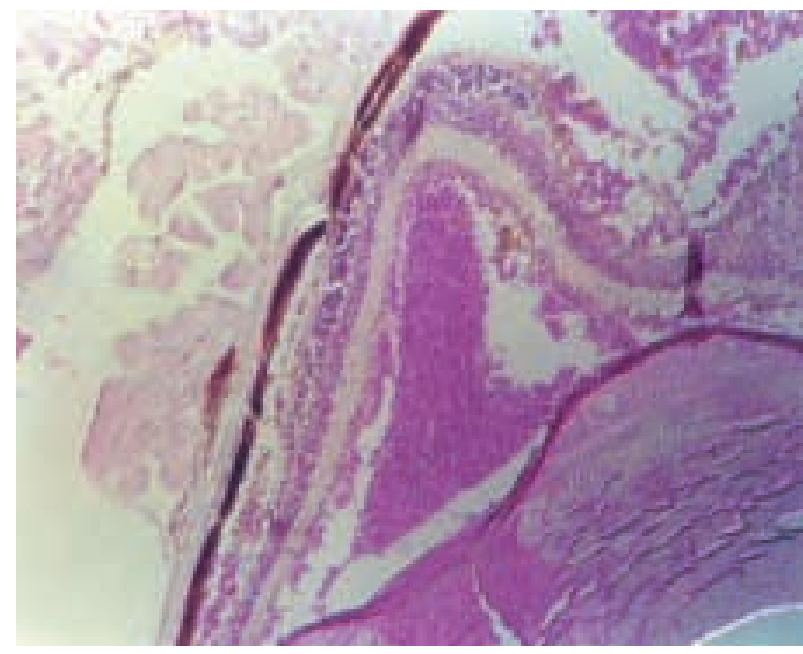

Fig. 3: Hemorragia.

lental (fig. 3), plegamiento (fig. 4) y en muchos casos pérdida de las capas constitutivas de la misma (fig. 3).

En los ratones negros (C57/BL) la capa uveal se vio seriamente afectada observándose un pleomorfismo celular del epitelio pigmentario (fig. 5) y presencia de gran cantidad de pigmentos extracelulares (fig. 6) que en algunos casos se acompañó de una ligera reacción inflamatoria principalmente polimorfonucleares es decir, eosinófilos (fig. 6). Igualmente se encontró vacuolización del epitelio no pigmentario de los procesos ciliares (fig. 6). En ratones blancos $(\mathrm{A} / \mathrm{J})$ sin embargo, la única manifestación observada en la capa uveal fue el aumento en la celularidad del iris y procesos ciliares. En un solo caso además de las serias lesiones de la retina, se observaron cambios profundos en el polo anterior, el cual presentó edema intenso en la capa

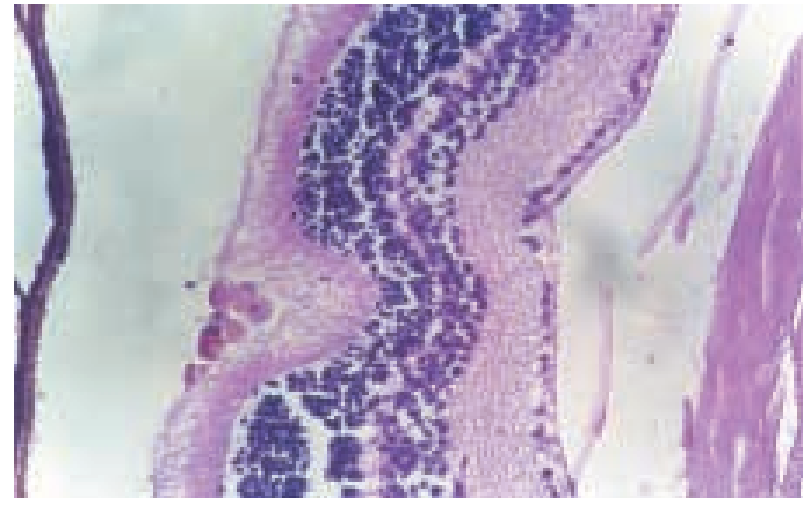

Fig. 4: Plegamiento. 


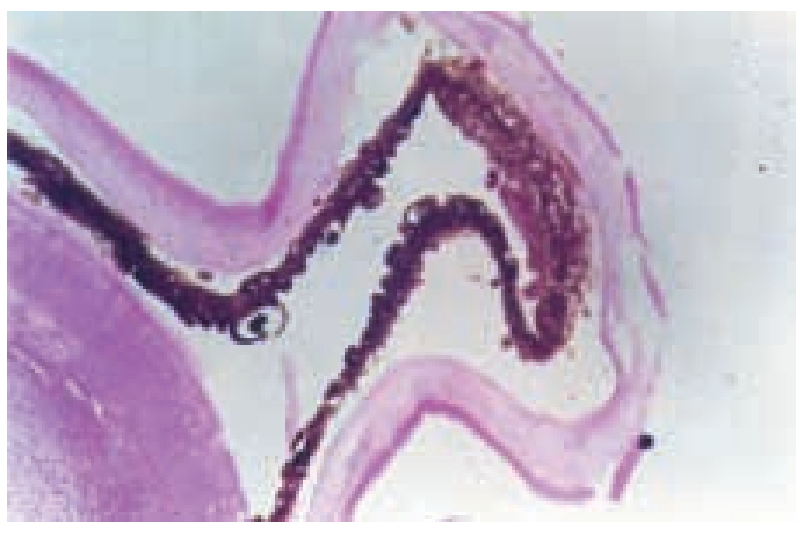

Fig. 5: Pleomorfismo del epitelio pigmentario.

propia de la córnea con amplios espacios entre los haces de colágeno e infiltrado inflamatorio. Igualmente este mismo animal presentó un material rosado fibrohialino que obliteró totalmente la cámara anterior con una respuesta inflamatoria granulomatosa constituida principalmente por eosinófilos.

El cristalino fue otra de las estructuras oculares que presentó alteraciones evidentes en su morfología normal tales como: vacuolización del epitelio anterior y en algunos casos atrofia del mismo. A pesar de las alteraciones producto de la infección por Toxocara canis, sólo en dos ratones uno blanco y otro negro se demostraron segmentos de larvas sin proceso inflamatorio alguno a su alrededor.

En ninguno de los animales estudiados se observó granuloma periférico en el polo posterior ni membranas hialinas retrolentales

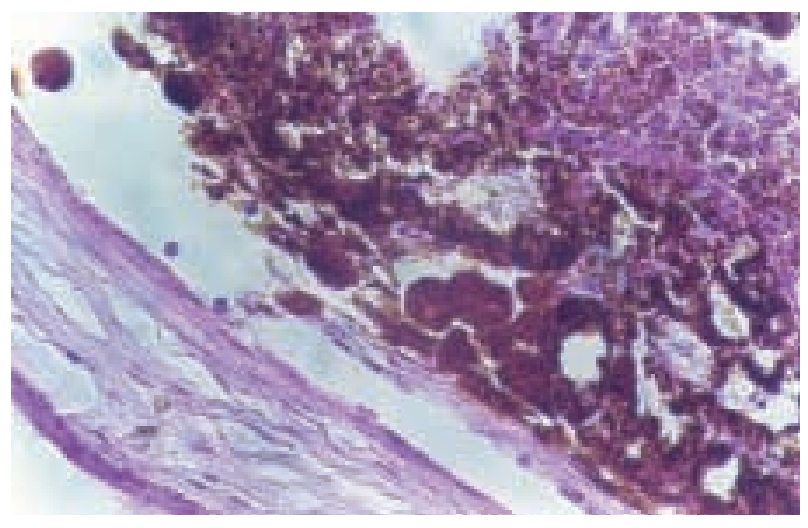

Fig. 6: Vacuolización en los procesos ciliares.

\section{DISCUSIÓN}

La infección en ratones $\mathrm{A} / \mathrm{J}$ y en ratones $\mathrm{C} 57 / \mathrm{BL}$ con Toxocara canis provocó importantes alteraciones histológicas a nivel de las estructuras celulares del ojo, las cuales fueron evidenciadas desde el séptimo día post-infección, ubicadas preferentemente a nivel del polo posterior.

La retina fue la estructura ocular mayormente afectada, cuya primera manifestación fue una edematización que avanzaba a medida que se prolongaba el tiempo de la infección, hasta llegar finalmente a una disgregación de sus capas una vez desorganizados todos los elementos celulares constituyentes. Estas alteraciones se acompañaron de una congestión de los vasos de la retina y hemorragia extensa, principalmente a nivel del espacio subretiniano y retrolental. Estos resultados coinciden con los hallazgos de quienes afirman que la retina es el sitio de impacto de la infección por Toxocara canis (6-8). Simultáneamente, Watzke RC y col habían encontraron alteraciones retinianas similares a las obtenidas en nuestro estudio conjuntamente acompañadas de perivasculitis, nódulos retinianos y uveítis (8).

De igual forma coincidimos con quienes señalaron que las alteraciones por este ascaridio no solo afectan la retina sino otras estructuras del polo posterior (19). Por otra parte, también se afecta el polo anterior como las observadas en cornea, cristalino y cámara anterior, donde notamos alteraciones histológicas de su citoarquitectura normal, acompañadas de edema intenso y reacción inflamatoria granulomatosa. Es importante recalcar los cambios observados en el cristalino, estructura ésta, pocas veces involucrada en las alteraciones resultantes de la infección por Toxocara canis. En nuestro caso, se vio afectado seriamente, encontrándose vacuolización del epitelio anterior, con disgregación de las fibras de su núcleo central, hecho no descrito en la literatura. Probablemente dichas alteraciones se deban a la opacidad del cristalino (1). Otro aspecto importante dentro de esta patología ocular, que involucró al cristalino, fue la atrofia del mismo observada en solo uno de los casos estudiados, alteración ésta igualmente no encontrada en la literatura revisada (1).

La dificultad que acarrea el diagnóstico de larva migrans ocular radica básicamente en la visualización de la larva de Toxocara canis en el tejido ocular. A pesar de ello tras la infección de ratones C57/BL con los huevos infectantes de Toxocara 
canis en un estudio realizado por Ghafoor et al encontraron 26 larvas de ascarideos en la retina y en los vasos retinianos (7). En nuestra investigación, sólo en dos casos se observaron larvas ubicadas en la retina, específicamente en la capa de conos y bastones sin reacción inflamatoria en la periferia. Este último hallazgo coincide, con otros experimentos realizados donde se observó después de nueve meses post-inoculación, larvas aparentemente viables sin reacción inflamatoria en la retina; igualmente las larvas estaban rodeadas por granulomas inflamatorios agudos o, granulomas fibróticos crónicos sin apariencia necrótica (8). Estos resultados sugieren que las larvas de Toxocara canis aparentemente se movilizan a través del tejido en cualquier etapa de la infección, siendo algunas de ellas atrapadas. Esta capacidad migratoria de las larvas fue comentada en estudios realizados en cerebro de roedores (10).

La presencia de alteraciones histológicas tan severas y la ausencia de larvas sugieren que las mismas son consecuencia de una respuesta tisular que involucran los mecanismos inmunológicos de defensa ante la infección tal como ocurre en otros casos de larva migrans visceral.

Es de resaltar que todas las alteraciones evidenciadas en nuestro estudio fueron observadas por lo general en ambos globos oculares pero con más intensidad en uno de ellos, hallazgos estos que contradicen las observaciones de quienes consideran la unilateralidad de las lesiones producto de la infección por Toxocara canis como la regla, con bilateralidad excepcional $(9,11,12)$.

\section{BIBLIOGRAFÍA}

1. Cordero Moreno R. Manifestaciones oculares de algunas enfermedades tropicales. Caracas: Publicaciones de la Secretaría de la U.C.V; 1993; 287.

2. Berrocal J. Prevalence of toxocara canis in babies and adults as determined by ELISA test. Trans Am Ophthalmol Soc 1980; 38: 376-413.

3. Sturchler D, Bruppacher R, Speiser F. Epidemiological aspects of toxocariasis in Switzerlard. Schweiz Med Wochenschr 1986; 116: 1088-1093.

4. Smith $M H$, Beaver PC. Persistence and distribution of Toxocara larvae in the tissues of children and mice. Pediatrics 1953; 12: 491-497.

5. Zyngier F. Histopathology of experimental toxocariasis in mice. Ann Trop Med Parasitol 1974; 68: 225-228.

6. Amos C. Posterior segment involvement in selected pediatric infectious diseases. J Am Optom Assoc 1979; 50: 1211-1220.

7. Ghafoor SY, Smith HV, Lee WR, Quinn R, Girdwood R. Experimental ocular toxocariasis: a mouse model. $\mathrm{Br} J$ Ophthalmol 1984; 68: 89-96.

8. Watzke RC, Oaks JA, Folk JC. Toxocara canis infection of the eye. Correlation of clinical observations with developing pathology in the primate model. Arch Ophthalmol 1984; 102: 282-291.

9. Searl SS, Moazed K, Albert DM, Marcus LC. Ocular toxocariasis presenting as leukocoria in a patient with low ELISA titer to toxocara canis. Ophthalmology 1981; 88: 1302-1306.

10. Abo-Shehada MN, Herbert IV. The migration of larval toxocara canis in mice II. Post-intestinal migration in primary infections. Vet Parasitol 1984; 17: 75-83.

11. Ashton N. Larval granulomatosis of the retina due to Toxocara. Br J Ophthalmol 1960; 44: 129-148.

12. Dernouchamps JP, Verougstraete C, Demolder E. Ocular toxocariasis: a presumed case of peripheral granuloma. Int Ophtalmol 1990; 14: 383-388. 